\title{
THE LABORATORY-ASSESSED PERFORMANCE PREDICTORS OF ELITE CROSS-COUNTRY MARATHON MOUNTAIN BIKERS
}

\author{
Everton Crivoi do Carmo ${ }^{1,2}$, Renato Barroso ${ }^{3}$, Danilo Marcelo Leite do Prado ${ }^{4}$, Allan Inoue \\ Tatiane Machado ${ }^{2}$, Cesar Cavinato Cal $\mathrm{Abad}^{6}$, Irineu Loturco ${ }^{6}$, and Valmor Tricoli ${ }^{1}$ \\ ${ }^{1}$ School of Physical Education and Sport - University of São Paulo, Brazil \\ ${ }^{2}$ Department of Physical Education, Senac University Center, São Paulo, Brazil \\ ${ }^{3}$ Department of Sport Sciences, School of Physical Education - University of Campinas, \\ Campinas, Brazil \\ ${ }^{4}$ Ultra Sports Science Lab, São Paulo, Brazil \\ ${ }^{5}$ Brazilian Navy, CEFAN, Research Laboratory of Exercise Science, Rio de Janeiro, Brazil \\ ${ }^{6}$ Nucleus of High Performance in Sports - NARSP, São Paulo, Brazil
}

Original scientific paper

DOI $10.26582 / \mathrm{k} .53 .2 .9$

\begin{abstract}
:
The study aimed to investigate the relationship between laboratory-assessed variables and crosscountry marathon mountain biking (XCM-MTB) performance to suggest a more practical approach to monitor performance during the competitive phase. Nine elite athletes performed a battery of tests during the competitive phase of the season, one week before the race. Correlations between the physiological and neuromuscular laboratory-assessed variables and mean race completion time were verified and a multiple regression model was calculated. Cycling economy $(\mathrm{r}=0.86)$, power output at the first (POVT1; $\mathrm{r}=-0.73)$ and second ventilatory threshold (POVT2; $\mathrm{r}=-0.94)$, VO2peak $(\mathrm{r}=-0.71)$, peak power output $(\mathrm{r}=-0.91)$; peak power $(\mathrm{r}=-0.80)$, and mean power $(\mathrm{r}=-0.85)$ were very strongly related to race performance. TMG-derivate factors as rectus femoris $(\mathrm{r}=-0.61)$ and biceps femoris $(\mathrm{r}=-0.59)$ contraction velocity, 30 -cm drop jump performance $(\mathrm{r}=-0.59)$, mean propulsive power in jump squat at $40 \%(\mathrm{JS} 40 \% ; \mathrm{r}=-0.65)$ and $60 \%(\mathrm{JS} 60 \%$; $\mathrm{r}=-0.62)$ of athlete's body weight and lower limbs maximal isometric voluntary strength $(\mathrm{r}=-0.59)$ were strongly related to race completion time. In an isolated way, the POVT2 explained $87 \%$ of race performance. Although both physiological and neuromuscular variables are related to XCM performance, the POVT2 seems to be the main variable during the competitive phase and an easy-to-apply approach should be used to monitor athletes' performance.
\end{abstract}

Key words: cycling, sports performance, muscle power, power output

\section{Introduction}

In the last few years, the mountain biking marathon (XCM) has become popular among recreational and competitive athletes. However, little is known about the modality, since most of the studies investigated Olympic cross-country mountain biking (XCO) (Bejder, Bonne, Nyberg, Sjoberg, \& Nordsborg, 2019; Granier, et al., 2018; Impellizzeri, Marcora, Rampinini, Mognoni, \& Sassi, 2005). However, an XCO race is more intense and shorter (80-100 minutes) compared to the XCM, where athletes cover between $60 \mathrm{~km}$ and $160 \mathrm{~km}$ with no restriction of time (UCI, 2019), which does not allow extrapolation of the results observed in the $\mathrm{XCO}$ to the XCM. Therefore, identifying the relationship between physiological and neuromuscular laboratory-assessed variables and XCM athletes' performance is important and may provide insights into real coaches and athletes' needs.

Engelbrecht and Terblanche (2018) found that performance in an 8-day multi-stage race was strongly correlated with absolute power output (PO) at lactate concentrations of $2 \mathrm{mmol} \cdot \mathrm{L}^{-1}(\mathrm{r}=-0.80)$ and $\mathrm{PO}$ at the onset of blood lactate accumulation $(\mathrm{r}=-0.75)$. Ahrend, Schneeweiss, Martus, Niess, and Krauss (2018) showed that PO in a 60-second maximal effort, the individual anaerobic threshold, and athlete's body weight explained $75 \%$ of the performance in XCM races. Novak, Bennett, Fransen, and Dascombe (2018) observed that in addition to the variables traditionally assessed in cycling tests as maximal oxygen consumption 
$\left(\mathrm{VO}_{2 \max }\right)$ and maximum PO sustained over the 60 seconds test, the peak left-hand grip strength and the response time for a two-line decision-making task also predicted the performance in a 4 -h race with good accuracy $\left(\mathrm{r}^{2}=0.99 ; \mathrm{p}<.01\right)$. Taken together, these studies suggest the multifactorial aspects of the XCM performance and a great variability of the predictive performance models.

As suggested by Novak et al. (2018), the XCM performance seems to be related to other parameters than that traditionally assessed in cyclists (Bejder, et al., 2019; Impellizzeri, et al., 2005; Inoue, Sa Filho, Mello, \& Santos, 2012; Novak, et al., 2018), among them some neuromuscular aspects. For instance, $\mathrm{PO}$ assessed by vertical jumps (Claudino, et al., 2017), mean propulsive power output (MPP) (Loturco, et al., 2015), maximal strength (Mujika, Ronnestad, \& Martin, 2016), and skeletal muscle contractile properties assessed by tensiomyography (Garcia-Garcia, Cuba-Dorado, Fernandez-Redondo, \& Lopez-Chicharro, 2018) have been suggested as sports performance predictors. Given they are associated with greater neural drive, intra- and intermuscular coordination, muscle-tendon, and muscle mechanical properties, they could result in a greater pedaling efficiency and, consequently, better cycling performance (Mujika, et al., 2016). However, the relationship between these neuromuscular aspects and athletes' XCM performance has not been studied.

Therefore, the first purpose of this study was to verify the level of association of the laboratory-assessed variables, including aerobic, anaerobic, and neuromuscular parameters, with athletes' performance in an XCM race. The second aim was to suggest a more specific and easy-to-apply approach to monitor performance during the competitive phase.

\section{Material and methods}

\section{Participants}

Nine high-performance mountain bikers $(28 \pm 7$ years of age, $1.73 \pm 0.7 \mathrm{~m}$ of height, and $64 \pm 6 \mathrm{~kg}$ of body mass; two women and seven men) participated in the study. All of them competed at national and international levels, including regional and national champions, with the participation in World Championships and Olympic Games. Four of them were classified as PL4-well-trained and five as PL5-professional (De Pauw, et al., 2013). This investigation was approved by the Institutional Review Board from the local University and all the athletes were informed of the experimental procedures, risks, and benefits, after which they signed an informed consent form before participating in the study.

\section{Experimental procedures}

This cross-sectional correlational study was performed in one laboratory and results from an XCM-MTB race were obtained. The data collection was performed during the competitive phase, in a single laboratory visit, one week before the main race. All athletes were previously familiarized with the testing procedures. The data collection commenced with the tensiomyography (TMG) assessment of $m$. vastus lateralis (VL), $m$. rectus femoris (RF), and $m$. biceps femoris (BF) of the athletes' dominant legs. Then, participants performed all vertical jump tests: squat jump (SJ), countermovement jump (CMJ), and drop jump from 30-cm (DJ30) and 45-cm (DJ45). After a 20-min rest interval, mean propulsive power output (MPP) in the jump squat (JS) and half squat (HS) exercises were measured. Five minutes later, the maximal voluntary isometric strength (MVIS) test was performed in the half-squat exercise. After at least one hour, participants completed submaximal cycling tests to determine cycling economy (CE) and gross efficiency (GE), and the maximal incremental test. One hour later, they performed the Wingate test.

\section{XCM-MTB race}

The XCM race, used as a performance criterion, was part of the Mountain Bike International Cup (Brazil) and scored points for the UCI ranking. The course was $64-\mathrm{km}$ in length with a total ascent of $1,573 \mathrm{~m}$. Race results were retrieved from the official organization public domain website available at https://cimtb.com.br/a-copa/resultados/ resultados-2018/

\section{Tensiomyography assessment protocol}

The muscle radial belly displacement (Dm; $\mathrm{mm}$ ), time of contraction (Tc; ms), and velocity of contraction $\left(\mathrm{Vc}, \mathrm{mm} \cdot \mathrm{ms}^{-1}\right.$ ) (Loturco, et al., 2016) were recorded using a tensiomyography device (TMG Measurement System, TMG-BMC Ltd., Ljubljana, Slovenia). An accurate pressure transducer (Trans-TekGK40, Panoptik d.o.o., Ljubljana, Slovenia) was positioned perpendicular to the muscle axis. The recording of the radial displacement took place in the muscle belly after an external electrical stimulus. To cause twitch responses, adhesive electrodes $5 \times 5 \mathrm{~cm}$ were connected to an electric stimulator and positioned on the skin surface above the muscle, according to the muscle fiber orientation. The electric pulse was set to $1 \mathrm{~ms}$ and the signal amplitude started at $30 \mathrm{~mA}$. For each pulse, the current amplitude was increased by 10 $\mathrm{mA}$, until the maximal displacement of the muscle belly was reached. Our TMG measurements coef- 
ficients of variation (CV) and intraclass correlation coefficients (ICCs) were from $2.7 \%$ to $4.7 \%$ and from 0.92 to 0.97 , respectively.

\section{Vertical jump tests}

In the SJ, athletes were required to achieve a squat position with $90^{\circ}$ of knee flexion and hold this position for $\sim 2$-s before jumping, without any preparatory movement. The range of movement was defined for each athlete and visually monitored by an experienced researcher. In the CMJ, athletes were instructed to execute a downward movement followed by a complete extension of the hip, knee, and ankle joints and were free to determine the countermovement amplitude to avoid changes in jumping coordination. In the DJ, athletes started from boxes of 30-cm (DJ30) and 45-cm (DJ45) and had to step off, land with both feet at the same time, and then jump. The reactive strength index (RSI, $\mathrm{m}^{-1} \mathrm{~s}^{-1}$ ) was calculated as jump height (meters) divided by ground contact time (seconds). All jumps were performed on a contact platform (Elite Jump, S2 Sports, São Paulo, Brazil), with the hands on the hips, and the athletes were instructed to jump as high as possible. Athletes performed five attempts of each jump test and the best attempt was used for the analyses.

\section{Mean propulsive power output}

Mean propulsive power outputs (MPP; W) were measured in the jump squat (JS) and half squat (HS) exercises, performed on a Smith Machine (Hammer Strength Equipment, Rosemont, USA). Athletes were instructed to execute three repetitions at maximal velocity for each load, with a 5-min rest interval between loads and the highest value was used for future analyses. The MPP at $40 \%$ and $60 \%$ of body mass in JS and $60 \%$ in HS were analyzed. These loads were selected as they represented the optimal load zone in the force-velocity curve of endurance athletes (Loturco, et al., 2015). During the JS, athletes squatted until their thighs were parallel to the ground and, after a verbal command, jumped as fast as possible without their shoulders losing contact with the bar. The HS was executed similarly to the JS, except that the participants were instructed to move the bar as fast as possible without losing foot contact with the ground. To determine MPP, a linear encoder (T-Force, Dynamic Measurement System; Ergotech Consulting S.L., Murcia, Spain) was attached to the Smith-Machine bar. The bar position data were sampled at $1,000 \mathrm{~Hz}$. The finite differentiation technique was used to calculate bar velocity and acceleration.

\section{Maximal voluntary isometric strength}

The maximal voluntary isometric strength (MVIS, N) was performed in HS exercise, with knee angle at $90^{\circ}$, in a Smith Machine (Hammer Strength Equipment, Rosemont, USA). The athletes were instructed to exert force as rapidly as possible against the mechanically fixed bar for five seconds and strong verbal encouragement was provided during the attempts. Forces were determined using a force platform with a custom-designed software (AccuPower; AMTI, Graz, Austria). The resultant force during exercise was calculated after subtracting the participant's weight (body mass $\mathrm{x}$ gravity acceleration). The MVIS, rate of force development (RFD, $\mathrm{N} \cdot \mathrm{s}^{-1}$ ) between 0-50 ms (RFD50) and between 0-100 ms (RDF100) were obtained and the best of two attempts was used for the analysis.

\section{Cycling tests}

All of the tests were performed on a mountain bike adjusted to the participant's preference and placed on an ergometer (Cyclus2 ergometer, RBM Electronics, Leipzig, Germany). During the constant load and maximal incremental tests, gas exchange measurements were assessed with a stationary gas analyzer (Metalyzer 3B, Cortex ${ }^{\circledR}$, Germany). The breath-by-breath values of $\mathrm{VO}_{2}$ were converted to averages of 30 seconds. The cycling economy (CE) was determined as the mean $\mathrm{VO}_{2}\left(\mathrm{~mL} \cdot \mathrm{kg}^{-1} \cdot \mathrm{min}^{-1}\right)$ during the last one minute of the 8 -min constant load test $(150 \mathrm{~W})$. The energy expenditure was determined (Brouwer, 1957) and the gross efficiency (GE, \%) was calculated by dividing total energy expenditure by power and multiplied by 100 .

The maximum incremental test started at 100 $\mathrm{W}$, with increments of $25 \mathrm{~W} \cdot \mathrm{min}^{-1}$ until volitional exhaustion. The cadence was maintained between 80 and $90 \mathrm{rpm}$ throughout the test, which was stopped when the athlete could not maintain the cadence or due to voluntary exhaustion. Ventilatory thresholds (VT1 and VT2) were determined according to Skinner and McLellan (1980). The VT1 was determined as the moment before the increase of both the ventilatory equivalent of oxygen (VE/ $\left.\mathrm{VO}_{2}\right)$ and the partial pressure of oxygen $\left(\mathrm{PETO}_{2}\right)$, concomitant with the first break in the linearity of ventilation (VE). The VT2 was determined by the lowest value of the ventilatory equivalent of carbon dioxide (VE/VCO2) before its increase and the highest pressure of $\mathrm{CO}_{2}$ at the end of expiration $\left(\mathrm{PETCO}_{2}\right)$ before its fall, concomitant with the second break in the linearity of VE. Peak oxygen consumption $\left(\mathrm{VO}_{2}\right.$ peak, $\left.\mathrm{mL} \cdot \mathrm{kg}^{-1} \cdot \mathrm{min}^{-1}\right)$ and the peak power output (PPO, W) was considered as the highest values in the last minute of the test.

Regarding the Wingate test, the athletes warmed up for five minutes at $60 \mathrm{rpm}$ with a load of $2 \%$ of body mass. After three minutes of rest, the participants started pedaling at maximal intensity for 30 seconds against the resistance of $7.5 \%$ of their body mass. Verbal encouragement was given throughout the test. Peak power (PP, W), peak cadence (PC, 
RPM), mean power (MP, W), and fatigue index (FI, \%) were determined.

\section{Statistical analysis}

Descriptive results are presented as mean \pm standard deviations and $95 \%$ of confidence interval $(95 \%$ CI). Data normality was checked through visual inspection and the Shapiro-Wilk test. The Pearson product-moment coefficient was used to analyze the level of association between the laboratory-assessed variables and race time. The correlation coefficients were interpreted as: $<0.1$, trivial; 0.1-0.3, small; 0.3-0.5, moderate; 0.5-0.7, strong, $0.7-0.9$, very strong; $>0.9$, nearly perfect. Multiple linear regression with the stepwise procedure was used to verify the level of determination between the analyzed variables. Initially, the measured variables were pooled into the neuromuscular variables and the cycling tests assessed variables. Following, the variables demonstrating the significant and nearly perfect correlation to the performance were selected and used in multiple linear regression. From the resulting multiple linear regression models, the models with all parameters showing a variance inflation factor (VIF) $<5$ and $\mathrm{p}<.05$ were considered. The statistical analysis was performed using the IBM SPSS statistical software package $v$. 20 (IBM Corp, New York, NY, USA).

\section{Results}

All the male athletes finished among the top 20, including the winner of the race. The two female athletes finished among the top five. The mean race completion time was $187.3 \pm 32.6$ min ranging from 149.1 to 239.3 minutes.

The neuromuscular-assessed variables are presented in Table 1.

The variables assessed in submaximal and maximal cycling tests are presented in Table 2.

Significant correlations with strong, very strong, and near-perfect associations between the laboratory-assessed variables and mean race completion time are shown in Table 3. The variables assessed in the cycling tests were significantly and nearly perfect or very strongly related to the mean race

Table 1. Contractile properties of the skeletal muscle, power, and strength tests variables

\begin{tabular}{|c|c|c|c|}
\hline Variables & Mean \pm SD & Range (min-max) & $95 \% \mathrm{Cl}$ \\
\hline \multicolumn{4}{|c|}{ Vastus lateralis (VL) } \\
\hline $\mathrm{TC}(\mathrm{ms})$ & $21.5 \pm 1.8$ & $19.2-25.2$ & $20.1-23.0$ \\
\hline $\mathrm{Dm}(\mathrm{mm})$ & $5.1 \pm 1.7$ & $2.7-8.7$ & $3.8-6.5$ \\
\hline $\operatorname{VC}\left(m \cdot \mathrm{s}^{-1}\right)$ & $0.1 \pm 0.03$ & $0.06-0.2$ & $0.08-0.1$ \\
\hline \multicolumn{4}{|c|}{ Rectus femoris (RF) } \\
\hline $\mathrm{TC}(\mathrm{ms})$ & $23.1 \pm 4.9$ & $15.2-30.1$ & $19.3-26.9$ \\
\hline $\mathrm{Dm}(\mathrm{mm})$ & $6.1 \pm 2.6$ & $2.8-9.9$ & $4.1-8.1$ \\
\hline $\operatorname{VC}\left(m \cdot \mathrm{s}^{-1}\right)$ & $0.1 \pm 0.05$ & $0.08-0.2$ & $0.08-0.2$ \\
\hline \multicolumn{4}{|c|}{ Biceps femoris (BF) } \\
\hline $\mathrm{TC}(\mathrm{ms})$ & $22.1 \pm 4.6$ & $13.6-29.3$ & $18.5-25.6$ \\
\hline $\mathrm{Dm}(\mathrm{mm})$ & $4.6 \pm 2.8$ & $1.2-9.0$ & $2.4-6.8$ \\
\hline $\operatorname{VC}\left(m \cdot \mathrm{s}^{-1}\right)$ & $0.09 \pm 0.05$ & $0.02-0.2$ & $0.05-0.1$ \\
\hline \multicolumn{4}{|l|}{ Jump tests } \\
\hline SJ $(\mathrm{cm})$ & $30.9 \pm 5.4$ & $21.8-37.6$ & $26.7-35.2$ \\
\hline $\mathrm{CMJ}(\mathrm{cm})$ & $31.9 \pm 5.8$ & $22.8-40.8$ & $27.4-36.4$ \\
\hline DJ30 (cm) & $31.1 \pm 6.3$ & $21.7-38.7$ & $26.3-36.0$ \\
\hline DJ30 RSI & $0.5 \pm 0.1$ & $0.4-0.8$ & $0.4-0.7$ \\
\hline DJ45 (cm) & $33.1 \pm 5.6$ & $24.9-40.1$ & $28.7-37.5$ \\
\hline DJ45 RSI & $0.6 \pm 0.1$ & $0.4-0.8$ & $0.5-0.7$ \\
\hline JS40 (W) & $390.8 \pm 68.9$ & $260.7-498.4$ & $337.7-443.7$ \\
\hline JS60 (W) & $513.9 \pm 106.2$ & $368.2-678.6$ & $432.2-595.5$ \\
\hline \multicolumn{4}{|l|}{ Half-squat } \\
\hline HS60 (W) & $420.3 \pm 103.2$ & $257.5-569.1$ & $341.0-499.7$ \\
\hline MIVS (N) & $1,745 \pm 399.8$ & $1,170-2,289$ & $1,435-2.050$ \\
\hline $\operatorname{RFD} 50\left(\mathrm{~N} \cdot \mathrm{s}^{-1}\right)$ & $9,946 \pm 4,873$ & $2,291-19,161$ & $6,199-13,692$ \\
\hline $\operatorname{RFD} 100\left(\mathrm{~N} \cdot \mathrm{s}^{-1}\right)$ & $7,440 \pm 3,203$ & $2,709-12,578$ & $4,977.8-9,902$ \\
\hline
\end{tabular}

Note. Mean \pm standard deviation (SD); $95 \% \mathrm{Cl}=$ confidence interval; $\mathrm{TC}=$ contraction time; $\mathrm{Dm}=$ radial muscle belly displacement; $\mathrm{VC}=$ velocity of contraction; $\mathrm{SJ}=$ squat jump; $\mathrm{CMJ}=$ countermovement jump; $\mathrm{DJ} 30=$ drop jump from $30 \mathrm{~cm} ; \mathrm{DJ} 45=$ drop jump from $45 \mathrm{~cm} ; \mathrm{RSI}=$ reactive strength index; BM = body mass; JS40 = mean propulsive power in jump squat at $40 \%$ of athlete's body weight; $\mathrm{JS} 60=$ mean propulsive power in jump squat at $60 \%$ of athlete's body weight; $\mathrm{HS} 60=$ mean propulsive power in half squat at $60 \%$ of athlete's body weight; MVIS = maximal voluntary isometric strength; RFD = rate of force development. 
Table 2. The submaximal, maximal and Wingate cycling tests assessed variables

\begin{tabular}{|c|c|c|c|}
\hline Variables & Mean \pm SD & Range (min-max) & $95 \% \mathrm{Cl}$ \\
\hline \multicolumn{4}{|c|}{ Submaximal constant load test } \\
\hline $\mathrm{CE}\left(\mathrm{mL} \cdot \mathrm{kg}^{-1} \cdot \mathrm{min}^{-1}\right)$ & $34.2 \pm 2.9$ & 29.9-38.1 & $32.0-36.5$ \\
\hline $\mathrm{CE}\left(\% \mathrm{VO}_{2 \text { peak }}\right)$ & $51.2 \pm 7.9$ & $43.1-67.5$ & $45.0-57.3$ \\
\hline GE (\%) & $19.2 \pm 0.6$ & $18.4-20.3$ & 18.7-19.7 \\
\hline \multicolumn{4}{|c|}{ Maximal incremental test } \\
\hline $\mathrm{VO}_{2} \mathrm{VT} 1\left(\mathrm{~mL} \cdot \mathrm{kg}^{-1} \cdot \mathrm{min}^{-1}\right)$ & $47.2 \pm 5.5$ & $38.9-55.2$ & $42.9-51.4$ \\
\hline$\% \mathrm{VO}_{2 \text { peak }}$ & $69.7 \pm 4.4$ & $64.4-76.7$ & $66.8-72.5$ \\
\hline POVT1 (W) & $250.0 \pm 39.5$ & $200-325$ & $219.6-280.3$ \\
\hline $\mathrm{VO}_{2} \mathrm{VT} 2\left(\mathrm{~mL} \cdot \mathrm{kg}^{-1} \cdot \mathrm{min}^{-1}\right)$ & $60.4 \pm 5.7$ & $48.7-66.3$ & $56.0-64.8$ \\
\hline$\% \mathrm{VO}_{2 \text { peak }}$ & $89.3 \pm 2.7$ & $85.7-94.6$ & $87.5-91.1$ \\
\hline POVT2 (W) & $338.8 \pm 53.1$ & $250-400$ & 297.9-379.7 \\
\hline 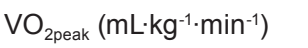 & $67.6 \pm 5.8$ & $56.4-73.6$ & $63.1-72.1$ \\
\hline PPO (W) & $398.1 \pm 65.5$ & $300-483$ & $347.7-448.4$ \\
\hline PPO rel $\left(W \cdot \mathrm{kg}^{-1}\right)$ & $5.9 \pm 0.5$ & $5.0-6.6$ & $5.5-6.3$ \\
\hline \multicolumn{4}{|l|}{ Wingate test } \\
\hline $\mathrm{PP}(\mathrm{W})$ & $811.7 \pm 146.9$ & 637.3-1015.8 & $698.8-924.6$ \\
\hline PP rel $\left(\mathrm{W} \cdot \mathrm{kg}^{-1}\right)$ & $12.1 \pm 1.2$ & $10.9-13.7$ & $11.2-13.1$ \\
\hline $\mathrm{MP}(\mathrm{W})$ & $660.6 \pm 100.5$ & $528.4-810$ & 583.3-737.9 \\
\hline PC (RPM) & $159.5 \pm 17.4$ & $130-186$ & $146.1-172.9$ \\
\hline FI (\%) & $43.1 \pm 5.4$ & $32.7-51.3$ & $38.9-47.2$ \\
\hline
\end{tabular}

Note. Mean \pm standard deviation (SD); $95 \% \mathrm{Cl}$ = confidence interval; CE = cycling economy; GE = gross efficiency; VT = ventilatory threshold; $\mathrm{PO}=$ power output; $\mathrm{VO}_{2}=$ oxygen consumption; $\mathrm{VO}_{2 \text { peak }}=$ peak oxygen consumption; $\mathrm{PPO}=$ peak power output; $\mathrm{PPO}$ rel = peak power output relative to body mass; PP = peak power; PP rel = relative peak power; MP = mean power; $\mathrm{PC}=$ peak cadence; $\mathrm{FI}$ = fatigue index; $\mathrm{W}=$ watts.

Table 3. Correlations between the laboratory-assessed variables and XCM-MTB race time

\begin{tabular}{|c|c|c|c|}
\hline Variables & $r(95 \% \mathrm{Cl})$ & p & \\
\hline $\mathrm{CE}\left(\mathrm{mL} \cdot \mathrm{kg}^{-1} \cdot \mathrm{min}^{-1}\right)$ & 0.86 (0.46 to 0.97$)$ & $<0.001$ & Very strong \\
\hline $\mathrm{CE}\left(\% \mathrm{VO}_{2 \text { peak }}\right)$ & 0.94 (0.73 to 0.99$)$ & $<0.001$ & Nearly perfect \\
\hline POVT1 (W) & $-0.73(-0.94$ to -0.13$)$ & 0.01 & Very strong \\
\hline 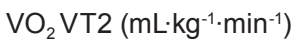 & $-0.80(-0.96$ to 0.29$)$ & $<0.001$ & Very strong \\
\hline POVT2 (W) & $-0.94(-0.96$ to -0.29$)$ & $<0.001$ & Nearly perfect \\
\hline $\mathrm{VO}_{2 \text { peak }}\left(\mathrm{mL} \cdot \mathrm{kg}^{-1} \cdot \mathrm{min}^{-1}\right)$ & $-0.71(-0.93$ to -0.09$)$ & 0.01 & Very strong \\
\hline PPO (W) & $-0.91(-0.98$ to -0.62$)$ & $<0.001$ & Nearly perfect \\
\hline PPO rel $\left(\mathrm{W} \cdot \mathrm{kg}^{-1}\right)$ & $-0.83(-0.98$ to -0.62$)$ & $<0.001$ & Very strong \\
\hline $\mathrm{PP}(\mathrm{W})$ & $-0.80(-0.96$ to -0.29$)$ & $<0.001$ & Very strong \\
\hline PP rel $\left(\mathrm{W} \cdot \mathrm{kg}^{-1}\right)$ & $-0.70(-0.93$ to 0.07$)$ & 0.01 & Very strong \\
\hline $\mathrm{MP}(\mathrm{W})$ & $-0.85(-0.97$ to 0.043$)$ & $<0.001$ & Very strong \\
\hline PC (RPM) & $-0.59(-0.9$ to 0.12$)$ & 0.04 & Strong \\
\hline $\operatorname{VCRF}\left(m \cdot \mathrm{s}^{-1}\right)$ & $-0.61(-0.91$ to 0.09$)$ & 0.04 & Strong \\
\hline $\operatorname{VCBF}\left(m \cdot \mathrm{s}^{-1}\right)$ & $-0.59(-0.9$ to 0.12$)$ & 0.04 & Strong \\
\hline DJ30 (cm) & $-0.59(-0.9$ to 0.12$)$ & 0.04 & Strong \\
\hline JS40 (W) & $-0.65(-0.92$ to 0.02$)$ & 0.02 & Strong \\
\hline JS60 (W) & $-0.62(-0.91$ to 0.08$)$ & 0.03 & Strong \\
\hline MIVS (N) & $-0.59(-0.9$ to 0.12$)$ & 0.04 & Strong \\
\hline
\end{tabular}

Note. $95 \% \mathrm{Cl}=$ confidence interval; $\mathrm{CE}=$ cycling economy; $\mathrm{VT}=$ ventilatory threshold; $\mathrm{PO}=$ power output; $\mathrm{VO}_{2}=$ oxygen consumption; $\mathrm{VO}_{2 \text { peak }}=$ peak oxygen consumption; $\mathrm{PPO}=$ peak power output; $\mathrm{PPO}$ rel = peak power output relative to body mass; $\mathrm{PP}=$ peak power; $\mathrm{PPrel}=$ relative peak power; $\mathrm{MP}=$ mean power; $\mathrm{PC}=$ peak cadence; $\mathrm{VC}=$ velocity of contraction; $\mathrm{RF}=\mathrm{m}$. rectus femoris; $\mathrm{BF}=\mathrm{m}$. biceps femoris; DJ30 = drop jump from $30 \mathrm{~cm}$; JS40 = mean propulsive power in jump squat at $40 \%$ of athlete's body weight; JS60 = mean propulsive power in jump squat at $60 \%$ of athlete's body weight; MVIS = maximal voluntary isometric strength. 
Table 4. Multi-variable predictive models for the XCM-MTB performance

\begin{tabular}{lcccccccc}
\hline Variable & $\begin{array}{c}\text { Adjusted } \\
\mathbf{r}^{2}\end{array}$ & $\begin{array}{c}\text { Std error of } \\
\text { estimate }\end{array}$ & $\mathbf{p}$ & $\mathbf{B}$ & Std error & Beta & tolerance & VIF \\
\hline Constant & & & & 392.588 & 27.818 & & & \\
POVT2 (W) & 0.875 & 12.21 & $<0.001$ & -0.612 & 0.81 & $-0,944$ & 1.000 & 1.000 \\
\hline
\end{tabular}

Note. POVT2 = power output at the second ventilatory threshold.

completion time. Regarding the neuromuscularassessed variables, the VCRF, VCBF, DJ30cm, JS40\%, JS60\%, and MIVS were also significantly and strongly correlated with the mean race completion time.

In the multiple linear regression, only variables demonstrating significant and nearly perfect correlation to the performance were included. Therefore, no neuromuscular variable was included in the analysis. Among the variables assessed in the submaximal and maximal cycling tests, $\mathrm{CE}\left(\% \mathrm{VO}_{2 \text { peak }}\right)$, POVT2 (W), and PPO (W) were included. The POVT2 was the only variable included in the multiple linear regression and it was able to explain $87 \%$ of the variance in the XCM performance (Table 4). All other variables did not meet the multicollinearity criteria and were excluded from the model.

\section{Discussion and conclusions}

The study aimed to investigate the level of association between the laboratory-assessed variables and performance in an XCM race to suggest a more practical approach to monitor performance during the competitive phase. Our findings indicate that the traditional variables assessed in cycling tests, including aerobic and anaerobic parameters, as well as some neuromuscular variables as VCRF, VCBF, $\mathrm{DJ} 30 \mathrm{~cm}$, JS40\%, BM, JS60\%, and MIVS, significantly correlate with the mean race completion time. However, the POVT2 was the only variable included in the multivariate analyses.

Regarding the submaximal cycling test variables, a positive correlation was observed between the CE, expressed relative to body mass, and the mean race completion time, and between the $\mathrm{CE}$ relative to $\mathrm{VO}_{2} \max$ and the mean race completion time. The $\mathrm{CE}$ is a useful metric for evaluating cycling performance as it represents a measure of efficiency determined by the amount of oxygen required to perform a given submaximal task (Lucia, Hoyos, Perez, Santalla, \& Chicharro, 2002). Another cycling efficiency measure is GE; however, despite the observed GE values (18.7\%-19.7\%) being similar to those previously reported (10\%-25\%) (Gaesser \& Brooks, 1975; Moseley, Achten, Martin, \& Jeukendrup, 2004), no significant correlation was observed with the mean race completion time. The role of GE as a predictor of cycling performance is questionable (Moseley, et al., 2004), and its relationship with performance was observed when esti- mated based on higher intensity tests (at the lactate threshold or the respiratory compensation point) (Faria, Parker, \& Faria, 2005), while we assessed GE at the intensity below the metabolic thresholds. Therefore, our results could be protocol influenced and future studies should investigate the role of GE in the XCM performance at higher intensities.

Significant negative correlations between the mean race completion time and POVT1, $\mathrm{VO}_{2} \mathrm{VT} 2$, POVT2, $\mathrm{VO}_{2}$ peak, and PPO support the suggestion that submaximal and maximal aerobic variables could be important to the XCM performance. Similar results were observed in XCO, where VT, $\mathrm{VO}_{2} \mathrm{max}$, and PPO were predictors of performance (Impellizzeri, et al., 2005). However, subtle differences emerge when correlation coefficients between the laboratory-assessed parameters and XCO and $\mathrm{XCM}$ are compared. For instance, Ahrend, Schneeweiss, Theobald, Niess, and Krauss (2016) showed a stronger correlation between $\mathrm{VO}_{2}$ max and the $\mathrm{XCO}$ performance $(\mathrm{r}=-0.86)$ when compared to $\mathrm{PO}$ at the individual anaerobic threshold and performance $(\mathrm{r}=-0.74)$. We observed a stronger negative correlation between POVT2 and the mean race completion time $(\mathrm{r}=-0.94)$ than between $\mathrm{VO}_{2}$ peak and the mean race completion time $(\mathrm{r}=-0.71)$. These results may be related to the differences in physiological demands imposed by the distinct MTB modalities. While in the XCO, $26 \pm 5 \%$ of the time is spent above maximal aerobic power (Granier, et al., 2018) and 80\% above the lactate threshold (Impellizzeri, Sassi, Rodriguez-Alonso, Mognoni, \& Marcora, 2002), in the $\mathrm{XCM}$, athletes cannot maintain intensity above the PPO for a long time (Wirnitzer \& Kornexl, 2008), and attempt to preserve energy stores (Novak, et al., 2018). Wirnitzer and Kornexl (2008) found that during the Translaps MTB marathon race athletes spent most of the time below blood lactate concentrations of $2 \mathrm{mmol} \cdot \mathrm{L}^{-1}(36 \pm 12 \%)$ and between $2-4$ $\mathrm{mmol} \cdot \mathrm{L}^{-1}(58 \pm 13 \%)$.

Ahrend et al. (2018) analyzed the predictive power of laboratory tests on XCM performance and observed large to very large correlations between race performance and the individual anaerobic threshold, which explained between $45 \%$ and $50 \%$ of performance, and PPO (53\%-59\%). However, the $\mathrm{PO}$ in the one-minute maximum effort cycling test explained between $68 \%$ and $72 \%$ of performance, which showed stronger correlations compared to the parameters traditionally evaluated by incre- 
mental tests. We also observed a simple association between maximal anaerobic sprints and performance given the PP, relative PP, MP, and PC assessed in a 30-second anaerobic test showed a significant negative correlation with the race completion time. This association could be explained by the need for a faster-start strategy, to allow a better positioning in the group in a massive-start race, and also by the need to overcome technical obstacles during the race (Abbiss, et al., 2013). However, it is noteworthy that only simple associations were observed, and these variables were not included in a model that could better explain performance. In addition, different from the XCO studies (Ahrend, et al., 2016; Bejder, et al., 2019), we did not observe a significant correlation between the fatigue index and the race completion time. Again, the differences may be related to the characteristics of the race, as XCO-MTB athletes are required to climb hills more often with a short recovery interval, which makes the fatigue index an important performance factor. In XCM, the recovery between hill climbs is longer and the importance of the fatigue index seems to be reduced.

The relationship between neuromuscular aspects and the XCM performance was proposed by Novak et al. (2018); however, the strength assessment was carried out in the handgrip exercise. In a more complete assessment, we observed strong negative correlations between DJ30cm, JS40\%, JS60\%, MIVS, and the mean race completion time. The importance of strength-power capacities in the XCM performance could be explained by high uphill and technical tracks, which require high force-low velocity muscle contractions (Abbiss, et al., 2013; Granier, et al., 2018). Athletes with higher strengthpower abilities can reduce the time to apply force in the pedals during the downstroke phase, thus increasing cycling efficiency (Sunde, et al., 2010). In addition, the effects of increased MIVS after a strength training program on cycling performance have been associated with a higher fatigue threshold of type I fibers and a delayed recruitment of type II fibers, reducing the anaerobic demand during long-distance events (Faria, et al., 2005; Mujika, et al., 2016). Therefore, higher strength and power capacities are important to increase cycling efficiency, decrease metabolic demands and improve performance.

Given Garcia-Garcia (2013) showed positive correlations between $\mathrm{VO}_{2 \max }$ and the TMG-derivate variables as Dm of $\mathrm{RF}(\mathrm{r}=0.637 ; \mathrm{p}<.05)$ and $\mathrm{Dm}$ of the BF $(r=0.680 ; p<.05)$ as well as between PPO and $\mathrm{Dm}$ of the BF $(r=0.652 ; \mathrm{p}<.05)$ in cyclists, we investigated the role of these muscles' mechanical properties as a predictor factor on the XCM performance. Isolated TMG variables were not associated with the mean race completion time. Nevertheless, we observed that $\mathrm{VC}$ in $\mathrm{RF}$ and $\mathrm{BF}$ were negatively correlated with the race completion time. Loturco et al. (2016) suggested that the VC is an important index to assess muscle functionality in top-level athletes. The correlation between VC in $\mathrm{BF}$ and performance could be explained by the role of $\mathrm{BF}$ in hip extension, acting with the knee extensors to improve pedaling efficiency. The BF also has an important contribution to the upstroke phase in a toe-clipped pedal, as in our study (Hug \& Dorel, 2009). The VC in RF and performance could be related to its activation (the knee extensor and hip flexor) and to its contribution to the joint stability and control of the direction of the pedal during the pedaling cycle. It showed the correlation between $\mathrm{RF}$ activation and $\mathrm{VO}_{2 \max }$ in a cycling test, suggesting the importance of this biarticular muscle in pedaling (Hug \& Dorel, 2009). Therefore, our TMG data suggest a possible role of biarticular muscles such as BF and RF on pedaling in highlevel cyclists; however, more studies are encouraged to verify the real importance of muscles $\mathrm{VC}$ on the $\mathrm{XCM}$ performance.

To improve our understanding of XCM and to identify key variables that affect performance in XCM races, we ran a multi-variable regression analysis by including in the model only variables with statistical significance and nearly perfect association with the race completion time (POVT2, $\mathrm{CE}$, and PPO). The POVT2 was the only variable in a final predictive model, as CE and PPO did not meet the multicollinearity criteria. The relationship between the metabolic thresholds and cycling performance is not new and is related to the athletes' ability to sustain high relative values of their $\mathrm{VO}_{2 \max }$ during a race (Jacobs, et al., 2011), which, due to the long distance in an XCM race, is the main factor in performance in this modality. In partial agreement with our results, Engelbrecht and Terblanche (2018) observed that the absolute $\mathrm{PO}$ at the onset of blood lactate accumulation was strongly correlated with race time $(\mathrm{r}=-0.75$; CI: -0.88 to -0.5 ). However, unlike the present result, the strongest predictor of performance was absolute $\mathrm{PO}$ at fixed lactate concentrations of $2 \mathrm{mmol} \cdot \mathrm{L}^{-1}$ $(\mathrm{r}=-0.80$; CI: -0.91 to -0.59$)$. The difference between the $\mathrm{PO}$ at the first and second metabolic threshold as the main predictor of race performance may be directly related to the race distance. The study by Engelbrecht and Terblanche (2018) was conducted during a multistage race, which was performed at a lower average exercise intensity compared to the one-day race (Wirnitzer \& Kornexl, 2008). Thus, we suggest that in a one-day XCM-MTB race the main predictor of performance should be the PO at the second ventilatory threshold. Therefore, in an easy-to-apply approach to monitoring athletes' performance during a competitive phase, coaches are encouraged to use simple and fast tests to verify the POVT2 (Borszcz, Tramontin, \& Costa, 2019; 
Nimmerichter, Williams, Bachl, \& Eston, 2010; Valenzuela, Morales, Foster, Lucia, \& de la Villa, 2018). However, it is worth noting that the results can be directly influenced by XCM races characteristics like length, altitude, and technical demands.

This study is not without limitations. We performed all tests on the same day. However, the observed values are in accordance with those observed in the literature. In addition, these are high-level athletes that are able to tolerate great exercise demands without apparent fatigue. It should be mentioned that our tests were performed during the competitive phase, and it is difficult for highlevel athletes and coaches to spend two or three days in laboratory assessments. In addition, our sample size (nine athletes) was small, which might have impacted our regression model and our model should not be used as a performance predictor. However, the aim of the study was not to effectively present a performance prediction regression, but to help coaches and sports scientists choose the best variables to monitor the performance during a competitive period. Therefore, among the great number of the variables analyzed in laboratory tests, the POVT2 appeared as a key performance variable in XCM, and trainers are encouraged to monitor closely this variable. Therefore, our results proposed a more practical approach to the laboratory-assessed variables during the competitive phase of the XCM athletes.

In practical terms, coaches and cyclists should focus on training strategies to improve their capacity to sustain a high level of submaximal aerobic work (that is, POVT2 intensity). In addition, during the competitive phase, a simple and fast method to evaluate the power output at the second metabolic threshold can be used by coaches and athletes.

Our results suggest that both the physiological and neuromuscular laboratory-assessed variables are strongly related to the XCM performance. However, during the competitive phase, the POVT2 explained up to $87 \%$ of the performance variance, which emphasized the importance of a well-developed aerobic system in a long-distance mountain biking race. Our results suggested a more easyto-apply approach involving only one variable to monitor the XCM athlete's performance.

\section{References}

Abbiss, C.R., Ross, M.L., Garvican, L.A., Ross, N., Pottgiesser, T., Gregory, J., \& Martin, D.T. (2013). The distribution of pace adopted by cyclists during a cross-country mountain bike World Championships. Journal of Sports Sciences, 31(7), 787-794. doi: 10.1080/02640414.2012.751118

Ahrend, M.D., Schneeweiss, P., Martus, P., Niess, A.M., \& Krauss, I. (2018). Predictive ability of a comprehensive incremental test in mountain bike marathon. BMJ - Open Sport and Exercise Medicine, 4(1), e000293. doi: 10.1136/bmjsem-2017-000293

Ahrend, M., Schneeweiss, P., Theobald, U., Niess, A.M., \& Krauss, I. (2016). Comparison of laboratory parameters of a mountain bike-specific performance test and a simulated race performance in the field. Journal of Science and Cycling, 5(1), 3.

Bejder, J., Bonne, T.C., Nyberg, M., Sjoberg, K.A., \& Nordsborg, N.B. (2019). Physiological determinants of elite mountain bike cross-country Olympic performance. Journal of Sports Sciences, 37(10), 1154-1161. doi: 10.1080/02640414.2018.1546546

Borszcz, F.K., Tramontin, A.F., \& Costa, V.P. (2019). Is the functional threshold power interchangeable with the maximal lactate steady state in trained cyclists? International Journal of Sports Physiology and Performance, 14(8), 1029-1035. doi: 10.1123/ijspp.2018-0572

Brouwer, E. (1957). On simple formulae for calculating the heat expenditure and the quantities of carbohydrate and fat oxidized in metabolism of men and animals, from gaseous exchange (Oxygen intake and carbonic acid output) and urine-N. Acta Physiologica et Pharmacologica Neerlandica, 6, 795-802.

Claudino, J.G., Cronin, J., Mezencio, B., McMaster, D.T., McGuigan, M., Tricoli, V., . ., \& Serrao, J.C. (2017). The countermovement jump to monitor neuromuscular status: A meta-analysis. Journal of Science and Medicine in Sport, 20(4), 397-402. doi: 10.1016/j.jsams.2016.08.011

De Pauw, K., Roelands, B., Cheung, S.S., de Geus, B., Rietjens, G., \& Meeusen, R. (2013). Guidelines to classify subject groups in sport-science research. International Journal of Sports Physiology and Performance, 8(2), 111-122. doi: 10.1123/ijspp.8.2.111

Engelbrecht, L., \& Terblanche, E. (2018). Physiological performance predictors in mountain bike multi-stage races. Journal of Sports Medicine and Physical Fitness, 58(7-8), 951-956. doi: 10.23736/S0022-4707.17.07139-0

Faria, E.W., Parker, D.L., \& Faria, I.E. (2005). The science of cycling: Factors affecting performance - part 2. Sports Medicine, 35(4), 313-337. doi: 10.2165/00007256-200535040-00003.

Gaesser, G.A., \& Brooks, G.A. (1975). Muscular efficiency during steady-rate exercise: effects of speed and work rate. Journal of Applied Physiology, 38(6), 1132-1139. doi: 10.1152/jappl.1975.38.6.1132.

García-García, O. (2013). The relationship between parameters of tensiomyography and potential performance indicators in professional cyclists. Revista Internacional de Medicina y Ciencias de la Actividad Física y el Deporte, 13(52), 771-781. 
Garcia-Garcia, O., Cuba-Dorado, A., Fernandez-Redondo, D., \& Lopez-Chicharro, J. (2018). Neuromuscular parameters predict the performance in an incremental cycling test. International Journal of Sports Medicine, 39(12), 909-915. doi: 10.1055/a-0644-3784

Granier, C., Abbiss, C.R., Aubry, A., Vauchez, Y., Dorel, S., Hausswirth, C., \& Le Meur, Y. (2018). Power output and pacing during international cross-country mountain bike cycling. International Journal of Sports Physiology and Performance, 13(9), 1243-1249. doi: 10.1123/ijspp.2017-0516

Hug, F., \& Dorel, S. (2009). Electromyographic analysis of pedaling: A review. Journal of Electromyography and Kinesiology, 19(2), 182-198. doi: 10.1016/j.jelekin.2007.10.010

Impellizzeri, F., Marcora, S., Rampinini, E., Mognoni, P., \& Sassi, A. (2005). Correlations between physiological variables and performance in high level cross country off road cyclists. British Journal of Sports Medicine, 39(10), 747-751. doi: 10.1136/bjsm.2004.017236

Impellizzeri, F., Sassi, A., Rodriguez-Alonso, M., Mognoni, P., \& Marcora, S. (2002). Exercise intensity during off-road cycling competitions. Medicine and Science in Sports and Exercise, 34(11), 1808-1813. doi: 10.1097/00005768200211000-00018

Inoue, A., Sa Filho, A.S., Mello, F.C., \& Santos, T.M. (2012). Relationship between anaerobic cycling tests and mountain bike cross-country performance. Journal of Strength and Conditioning Reserch, 26(6), 1589-1593. doi: 10.1519/ JSC.0b013e318234eb89

Jacobs, R.A., Rasmussen, P., Siebenmann, C., Diaz, V., Gassmann, M., Pesta, D., . ., \& Lundby, C. (2011). Determinants of time trial performance and maximal incremental exercise in highly trained endurance athletes. Journal of Applied Physiology (1985), 111(5), 1422-1430. doi: 10.1152/japplphysiol.00625.2011

Loturco, I., Gil, S., Laurino, C.F., Roschel, H., Kobal, R., Cal Abad, C.C., \& Nakamura, F.Y. (2015). Differences in muscle mechanical properties between elite power and endurance athletes: A comparative study. Journal of Strength and Conditioning Reseach, 29(6), 1723-1728. doi: 10.1519/JSC.0000000000000803

Loturco, I., Pereira, L.A., Kobal, R., Kitamura, K., Ramirez-Campillo, R., Zanetti, V., . ., \& Nakamura, F.Y. (2016). Muscle contraction velocity: A suitable approach to analyze the functional adaptations in elite soccer players. Journal of Sports Science and Medicine, 15(3), 483-491.

Lucia, A., Hoyos, J., Perez, M., Santalla, A., \& Chicharro, J.L. (2002). Inverse relationship between VO2max and economy/efficiency in world-class cyclists. Medicine and Science in Sports and Exercise, 34(12), 2079-2084. doi: 10.1249/01.MSS.0000039306.92778

Moseley, L., Achten, J., Martin, J., \& Jeukendrup, A. (2004). No differences in cycling efficiency between world-class and recreational cyclists. International Journal of Sports Medicine, 25(05), 374-379. doi: 10.1055/s-2004-815848

Mujika, I., Ronnestad, B.R., \& Martin, D.T. (2016). Effects of increased muscle strength and muscle mass on endurancecycling performance. International Journal of Sports Physiology and Performance, 11(3), 283-289. doi: 10.1123/ IJSPP.2015-0405

Nimmerichter, A., Williams, C., Bachl, N., \& Eston, R. (2010). Evaluation of a field test to assess performance in elite cyclists. International Journal of Sports Medicine, 31(3), 160-166. doi: 10.1055/s-0029-1243222

Novak, A.R., Bennett, K.J.M., Fransen, J., \& Dascombe, B.J. (2018). Predictors of performance in a 4-h mountain-bike race. Journal of Sports Sciences, 36(4), 462-468. doi: 10.1080/02640414.2017.1313999

Skinner, J.S., \& McLellan, T.H. (1980). The transition from aerobic to anaerobic metabolism. Research Quarterly for Exercise and Sport, 51(1), 234-248.

Sunde, A., Storen, O., Bjerkaas, M., Larsen, M.H., Hoff, J., \& Helgerud, J. (2010). Maximal strength training improves cycling economy in competitive cyclists. Journal of Strength and Conditioning Research, 24(8), 2157-2165. doi: 10.1519/JSC.0b013e3181aeb16a

UCI. (2019). UCI cycling regulations: Part IV Mountain bike races. Aigle: Union Cycliste Internationale. Retrieved February 11, 2020 from https://www.uci.org/regulations/3MyLDDrwJCJJ0BGGOFzOat\#part-iv-mountain-bike

Valenzuela, P.L., Morales, J.S., Foster, C., Lucia, A., \& de la Villa, P. (2018). Is the functional threshold power a valid surrogate of the lactate threshold? International Journal of Sports Physiology and Performance, 13(10), 12931298. doi: 10.1123/ijspp.2018-0008

Wirnitzer, KC., \& Kornexl, E. (2008). Exercise intensity during an 8-day mountain bike marathon race. European Journal of Applied Physiology, 104(6), 999-1005. doi: 10.1007/s00421-008-0855-y

Submitted: July 22, 2020

Accepted: October 22, 2021

Published Online First: December 3, 2021
Correspondence to:

Everton C. do Carmo, Ph.D.

Department of Physical Education, Senac University Center

Av. Engenheiro Eusébio Stevaux, 823 - Santo Amaro, Brazil

Phone: +55 11 5682-7494; Fax: +55 11 5682-7441

E-mail: evertoncrivoi@usp.br

\section{Acknowledgments}

The authors thank the participants in the study and all the researchers involved in the data collection. 